\title{
The method of correlation selection based on IQ and EQ measurements for assessing the psychological stability of a person
}

\author{
Katerina Kolesnykova, Tatyana Koycheva, Ivan Donchev, Arnold Kiv \\ South-Ukrainian National Pedagogical University named after K.D. Ushinsky, 65020 \\ Odessa, Ukraine
}

\begin{abstract}
:
In this paper, it is proposed to evaluate the psychological stability of the individual on the basis of correlations of IQ and EQ characteristics. 56 of middle-aged employees of a technical enterprise were tested. Then 3 groups were formed with different mean values of the IQ parameter. It turned out that the highest values of the correlation coefficients of IQ and EQ characteristics are observed in the group with the lowest values of the IQ parameter. The method of correlation selection based on IQ and EQ measurements is proposed. The created computer program allows revealing the influence of each member of the group on the average correlation coefficient and thus, excluding the members of the group that most strongly lower the correlation coefficient, we bring the correlation coefficient to the desired value. Excluded members of the group may be a subject to additional psychological research.
\end{abstract}

Keywords: Introduction: Psychological stability of the individual 
20-22 March, 2020

Berlin, Germany $10^{\text {th }}$ International Conference on

Humanities, Psychology \& Social Sciences

\section{Introduction:}

Psychological stability of the individual is formed with the accumulation of the life experience of personality and depends on various factors, such as the type of human nervous system, the level of cognitive abilities etc. [1 - 3].

In this research, we are interested to consider the psychological stability of the individual as an adequate response to an external stimulus of the intellectual nature, for example, to a humorous statement. We believe that in this case the correlation of IQ and EQ characteristics is significant. Indeed, the correct and deep assessment of a particular utterance depends on the IQ parameter, and an adequate emotional response depends on the EQ parameter. Psychological stability in question depends substantially on the age of the individual $[4,5]$. Our research relates to middle-aged people.

The goal of our study was to find out the effect of the value of IQ parameter on the correlation between the parameters IQ and EQ, suggesting that a good correlation between these parameters means a high psychological stability of the personality. We emphasize that we mean psychological stability in relation to external stimuli of the intellectual nature.

\section{Subjects and procedure}

The study was conducted with the participation of 56 employees of the enterprise of technical profile. All participants in the experiment are highly qualified in their field. In the experiment, approximately two thirds of the men and one third of the women participated. The participants in the experiment were tested according to the Eysenck method [6] for determining the parameter IQ and according to the method of Lyusin [7] for determining the parameter EQ.

Then the whole group was divided into three subgroups with the highest, medium and low values of the parameter IQ $(114,83 ; 107,47 ; 98,74)$. At the next stage, the coefficient $\mathrm{R}^{2}$ was calculated. Since in all subgroups the value of this coefficient turned out to be below than desired, the so-called correlation selection method (CSM) was proposed and applied.

\section{Correlation selection analysis of subgroups}

A computer program was written, the algorithm of which envisaged alternately deleting each member from the subgroup list and calculating the correlation coefficient without the removed member, then returning it and deleting the next member of the subgroup and 
20-22 March, 2020

Berlin, Germany $10^{\text {th }}$ International Conference on

Humanities, Psychology \& Social Sciences

again calculating the correlation coefficient, etc. Thus, it is possible to identify the members of the subgroup that most significantly worsen the correlation. Next, using this list, the required number of points is deleted (see Fig. $1-3$ and Table 1) to achieve the desired value of the parameter $\mathrm{R}^{2}\left(\right.$ In our case $\left.\mathrm{R}^{2} \approx 0.95\right)$.

\section{Results and discussion}

As a result of this study, it turned out that the best correlation between IQ and EQ characteristics occurs for the subgroup with the lowest average value IQ. It can be assumed that this is due to the fact that in the case of a larger value of the parameter IQ, an adequate emotional reaction to the intellectual stimulus is blocked by certain logical considerations of the individual.

It is important to note that the result obtained relates to the case of the influence of an intellectual external stimulus on the individual. In the case of other external influences, other patterns of the influence of the IQ value on the correlation of IQ and EQ parameters may appear.

From Table 1, it can be seen that when moving from the first subgroup to the third, the number of deleted points decreases (in CSM). Deleted by using the CSM, team members are subject to a special psychological study to ascertain their features that determine their negative effect on the correlation. The proposed approach can be applied to the study of the psychological characteristics of the team.

\section{Conclusion}

- It is assumed that in the case an external stimulus of the intellectual nature the psychological stability of the individual is determined significantly by the correlation of IQ and EQ characteristics of a personality.

- It was found that in the team with a smaller average value of IQ parameter, the best correlation between parameters IQ and EQ takes place. This is true for the external influence of the intellectual nature.

- The proposed method of correlation selection can be used to study the team in terms of psychological stability with respect to external stimuli of the intellectual nature (identifying team members with specific psychological features). 
20-22 March, 2020

Berlin, Germany $10^{\text {th }}$ International Conference on

Humanities, Psychology \& Social Sciences

\section{References}

1. McCrae, Robert R., and Paul R. Costa Jr.: A Five-Factor Theory of Personality. In Handbook of Personality Theory and Research: Lawrence A. Pervin and Oliver P. John. (eds.) 139-153.2nd. New York: Guilford. (1999)

2. Roberts, Brent W., and Wendy F. Del Vecchio.: The Rank-order Consistency of Personality Traits from Childhood to Old Age: A Quantitative Review of Longitudinal Studies. Psychological Bulletin 126: 3-25. (2000)

3. Jeffries, E.R., McLeish, A.C., Kraemer, K.M., Avallone, K.M., Fleming, J.B.: The Role of Distress Tolerance in the Use of Specific Emotion Regulation Strategies. Behavior Modification, 40 (3), 439-451. (2015)

4. M. Chaturvedi and R. Chander.: Development of emotional stability scale, Ind Psychiatry J. Jan-Jun; 19(1): 37-40 (2010)

5. Volov V.T., Volov V.V.: Research of psycho-emotional stability in the basal emotions matrix, National Psychological Journal. 4, 98-107 (2016)

6. Eyesenk, H., Wilson, H.: How to measure personality. M.: Kogito-Tsentr, p. 284 (2010); Lyusin D. V.: Psikhologicheskaya diagnostika. 4, 3-22., (2006)

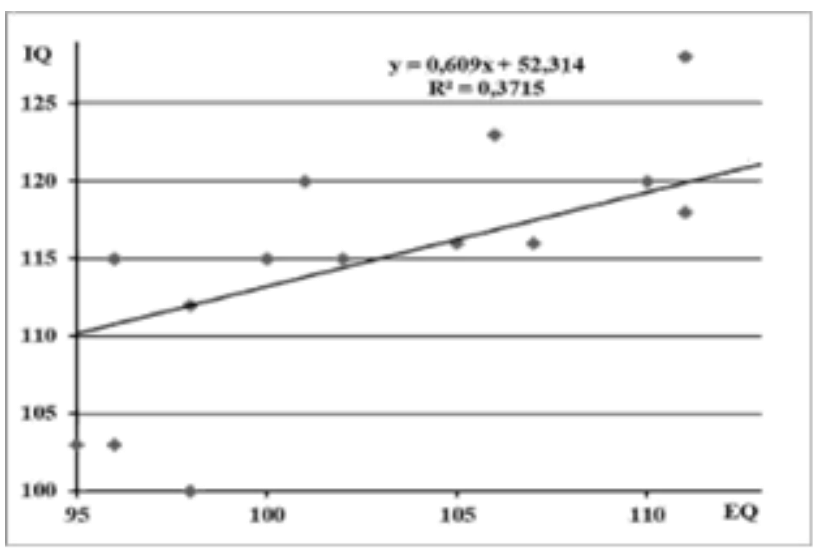

Fig 1a IQ-EQ dependence before selection for group 1

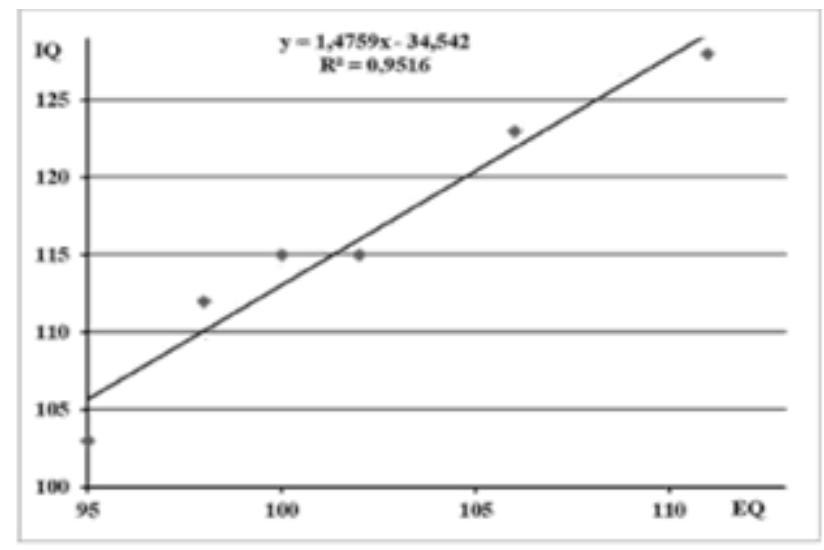

Fig 1b IQ-EQ dependence after selection for group 1 
20-22 March, 2020

Berlin, Germany $10^{\text {th }}$ International Conference on Humanities, Psychology \& Social Sciences

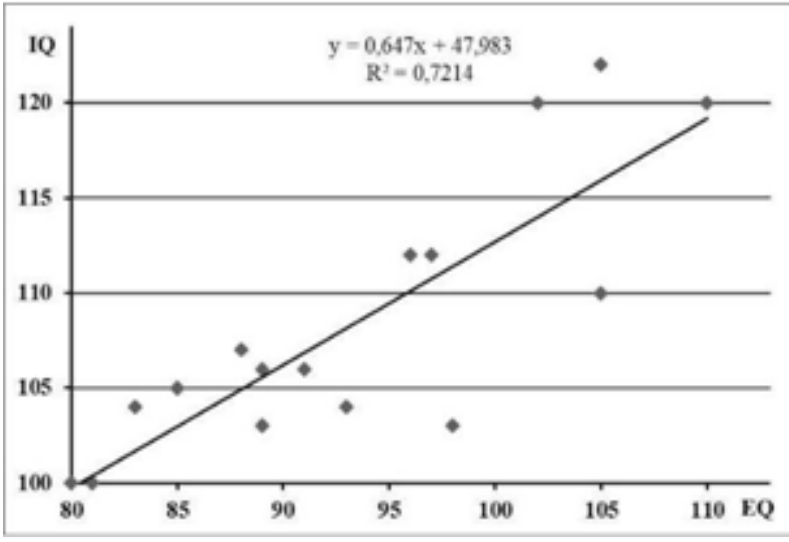

Fig 1a IQ-EQ dependence before selection for group 2

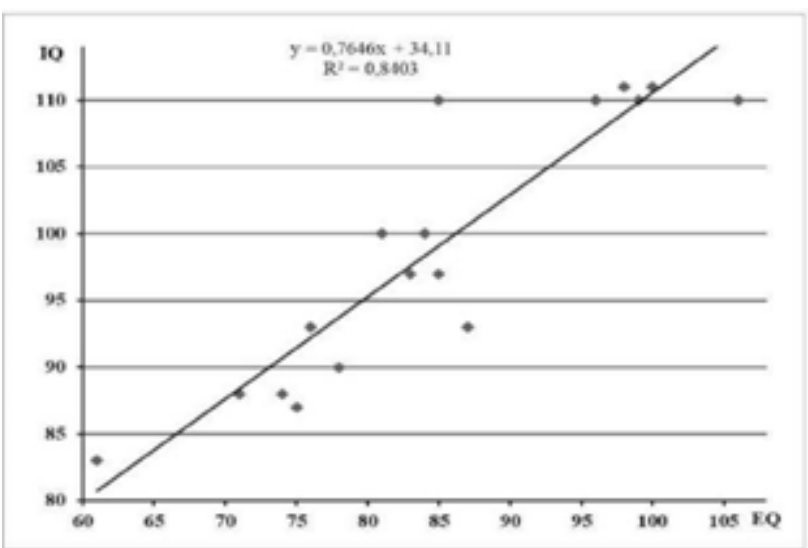

Fig 1a IQ-EQ dependence before selection for group 3

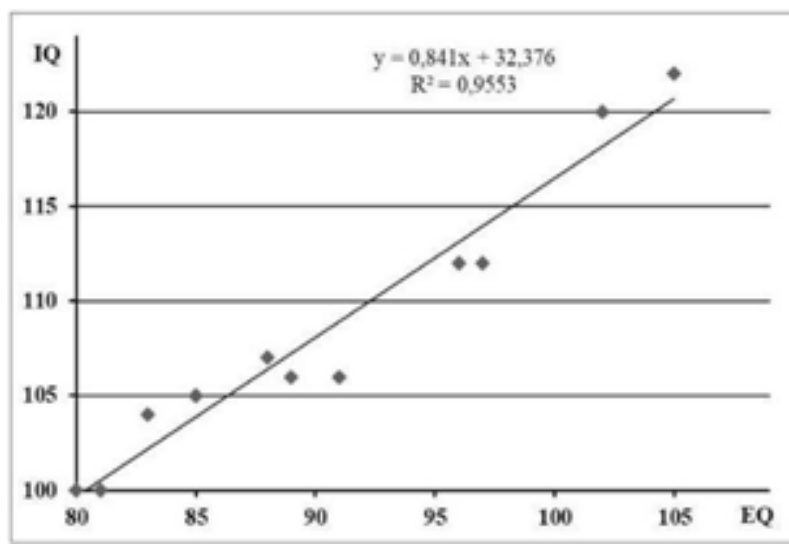

Fig 1b IQ-EQ dependence after selection for group 2

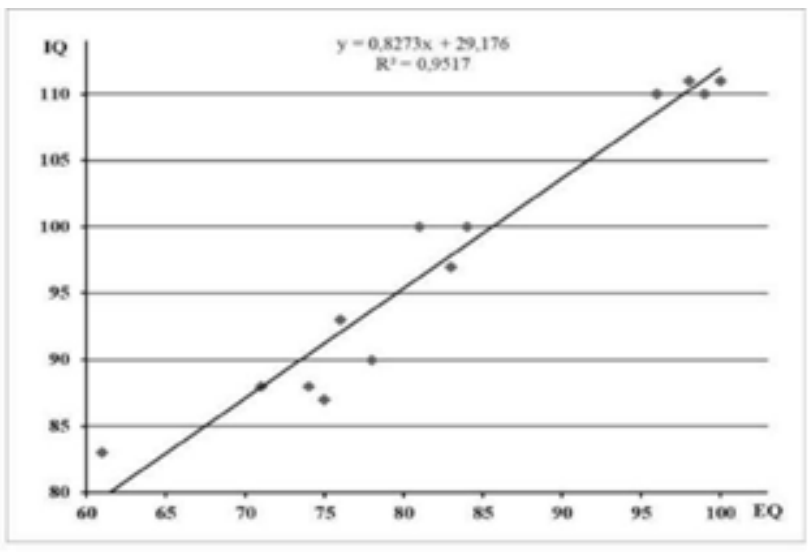

Fig 1b IQ-EQ dependence after selection for group 3

Note: Some points for different participants of experiment are the same. That is why the number of points in Figures is not equal to the number of participant of experiment. 
20-22 March, 2020

Berlin, Germany $10^{\text {th }}$ International Conference on

Humanities, Psychology \& Social Sciences

Table 1 The results of the correlation selection of individuals

\begin{tabular}{|c|c|c|c|}
\hline Groups & G1 & G2 & G3 \\
\hline IQ average & 114,83 & 107,47 & 98,73 \\
\hline $\begin{array}{l}\mathrm{R}^{2} \text { before } \\
\text { selection }\end{array}$ & 0,3715 & 0,7214 & 0,8403 \\
\hline $\begin{array}{c}\mathrm{R}^{2} \text { after } \\
\text { deleting of } \boldsymbol{n} \\
\text { points }\end{array}$ & $\begin{array}{r}0,9516 \\
n=12\end{array}$ & $\begin{array}{l}0,9553 \\
n=6\end{array}$ & $\begin{array}{l}0,9517 \\
n=4\end{array}$ \\
\hline \multicolumn{4}{|c|}{$\begin{array}{l}\text { Average age of men and } \\
\text { women }\end{array}$} \\
\hline $\mathrm{M}$ & 41 & 47 & 42 \\
\hline $\mathrm{W}$ & 34 & 38 & 32 \\
\hline \multicolumn{4}{|c|}{$\begin{array}{l}\text { Number of } \\
\text { persons }\end{array}$} \\
\hline $\mathrm{M}$ & 13 & 15 & 12 \\
\hline $\bar{W}$ & 5 & 4 & 7 \\
\hline Total & 18 & 19 & 19 \\
\hline
\end{tabular}

